Fecha de recepción: agosto 2008 Fecha de aceptación: marzo 2009 Versión final: diciembre 2010

\section{La Celestina en la versión de Daniel Suárez Marzal: apuntes sobre su puesta en escena}

Andrés Olaizola *

\begin{abstract}
Resumen: En septiembre de 2007 se estrenó en el Teatro Regio La Celestina, en la versión escrita y dirigida por Daniel Suárez Marzal. La puesta en escena del clásico de Fernando de Rojas es producto de una lectura que privilegia un diálogo entre el pasado y el presente. La Celestina de Suárez Marzal no es una puesta "historicista" ni una puesta completamente "contemporánea", antes bien se desarrolla a partir de la síntesis y la reconfiguración de determinados aspectos dramáticos y escénicos tanto clásicos y como actuales. El siguiente trabajo analiza los diferentes elementos que entran en juego en la puesta en escena de Suárez Marzal de la pieza de Fernando de Rojas.
\end{abstract}

Palabras claves: directores teatrales argentinos - Fernando de Rojas - hibridación genérica - puesta en escena - teatro clásico - teatro postmoderno.

[Resúmenes en inglés y portugués y currículum en las páginas 29-30]

\title{
Introducción
}

A lo largo del tiempo la Tragicomedia de Calisto y Melibea (circa 1500-1507) ha tenido múltiples adaptaciones, versiones y puestas en escena. En el siguiente trabajo analizaremos algunos aspectos de La Celestina, la versión escrita y dirigida por Daniel Suárez Marzal que fue estrenada en septiembre de 2007 en el Teatro Regio de la Ciudad de Buenos Aires.

\section{La cuestión del género}

Antes de desarrollar las consideraciones sobre la puesta en escena de Daniel Suárez Marzal es necesario dar cuenta brevemente de la polémica que suscita la definición del género discursivo de la obra de Fernando de Rojas.

A grandes rasgos hay dos posiciones predominantes con respecto al género de La Celestina: la posición que subraya el carácter dramático de la pieza, y la que considera a la obra como una proto-novela. A partir de un análisis sobre el amor cortés y la moral en el desarrollo de la acción de la pieza Ottis Green (1991: 506) afirma que "La Celestina es una obra dramática, no lírica, y tiene que precipitarse su desenlace mediante la acción rápida y vengadora de la muerte".

Ian Macpherson (2001) desarrolla una perspectiva intermedia sobre la cuestión genérica. Si bien afirma que La Celestina no pertenece a ningún género tradicional, Macpherson (2001: 547) sostiene que la obra "fue escrita en forma dialogada para ser leída en voz alta". La Celestina no seguiría el modelo de la narrativa sentimental, como por ejemplo Cárcel de amor (1492), pero tampoco se presentaría como un texto puramente dramático ya que no entraría en juego la representación. 
En contraposición Dorothy Severin (1994: 27) retoma la hipótesis de Alan Deyermond (1978) y argumenta que Fernando de Rojas halló una comedia humanística incompleta y decidió completarla "no como tal comedia sino como una novela sentimental paródica y dialogada que sea al mismo tiempo trágica y cómica".

La hibridación genérica de la pieza es lo que favorece la versión y la puesta de Suárez Marzal. La multiplicidad de interpretaciones posibles que pueden realizarse sobre el género de La Celestina sostendría una adaptación, una síntesis del texto basada en una estructura dramática contemporánea. La estructura abierta y polisémica de la obra original permitiría diversos acercamientos y lecturas. Justamente Suárez Marzal (Cabrera, 2007) afirma que "La Celestina no es originalmente una pieza teatral, sino una novela dialogada que decidí asentar sobre tres personajes, como si fuera una obra de estos días, con economía de medios y de estructura".

\section{La puesta en escena de Suárez Marzal}

Bertolt Brecht (1976) afirmaba que las grandes obras del pasado no son intocables, son una herencia a partir de la cual debe generarse algo productivo (Ivernel, 1967: 178-179). La versión de Suárez Marzal formaría parte de la serie de lecturas postmodernas de textos clásicos, es decir, que su tipo de puesta de escena se enmarcaría en los lineamientos del teatro postmoderno (De Toro, 1999: 156). Las interpretaciones en clave postmoderna de los textos del teatro clásico establecen un fructífero y poderoso diálogo pasado/presente. A través de un enfoque deconstruccionista se recrea y rescribe el texto en todas o en algunas de sus dimensiones. Las adaptaciones, versiones, "homenajes" y demás prácticas discursivas presentan un "nuevo" texto donde pueden escucharse los ecos del pasado.

\section{Personajes}

La Celestina de Suárez Marzal se basa en una triada conformada por Melibea (Julieta Díaz), Calisto (Sergio Surraco) y Celestina (Elena Tasisto). La pieza gira alrededor de la historia de los amantes y cómo ellos utilizan y son utilizados por Celestina para concretar su amor. Puesto que se omiten los otros once personajes de la Tragicomedia, a menudo Calisto, Melibea o Celestina citan directa o indirectamente las voces de los otros. El ejemplo más paradigmático es el planto de Pleberio; en la puesta de Suárez Marzal es Melibea quien pronuncia, justo antes de su muerte, las palabras de su padre. A su vez los criados de Calisto, Sempronio y Pármeno, tan sólo son mencionados por Celestina mientras agoniza.

En la Tragicomedia está presente la idea del amor como una peligrosa enfermedad, como una fuerza poderosa que lleva a los enamorados a la pérdida de la razón, a la locura y finalmente a la muerte (Macpherson, 2001: 547). En gran medida esta concepción es explicitada por los criados de los enamorados: Sempronio se burla de su amo, "destemplado está esse laúd" $(91)^{1}$, o directamente lo cataloga de loco: “En sus treze está este necio!” (101). Para la criada Lucrecia, Melibea también está loca: "El seso tiene perdido mi señora" (242). Además, la Tragicomedia presentaría la pareja de Pármeno y Areúsa como la parodia de la pareja de los trágicos enamorados, un espejo realista "enfrentando a los amores de Calisto y Melibea, un amor que echa mano de la rimbombante retórica de la novela sentimental para velar una sexualidad como la que más" (Severin, 1994: 33).

$\mathrm{Al}$ omitir a los criados, la puesta de Suárez Marzal deja de lado el elemento paródico, las burlas al amor de Calisto y Melibea, aunque no el humor. El amor no se presenta como una enfermedad peligrosa, en la versión de Suárez Marzal se desarrolla como una fuerza, una pulsión vital que mueve a los personajes por sobre normas familiares, morales o sociales. Suárez Marzal (Cabrera, 2007) 
explica que "en La Celestina me concentré en esa relación de tres, rescatando los aspectos cómicos que conducen a la tragedia y el sentido medieval de la danza de la muerte que es guiada por el dios Eros". Calisto y Melibea se sumergen en ese torrente que ha nacido entre los dos, establecen una sinergia que retroalimenta su vida y por ende su amor. Pero la fuerza del amor, al mismo tiempo que desborda y enriquece sus existencias vitales, no puede ser controlada. El destino trágico está establecido: los personajes son destruidos por una fuerza más allá de ellos mismos, una fuerza que los sobrepasa y los termina ahogando.

\section{Escenografía}

La puesta de Suárez Marzal presenta una escenografía fija y despojada de objetos, casi minimalista. Pueden rastrearse ciertas influencias de la planta de los antiguos corrales de comedia, los cuales estaban desprovistos de elementos ${ }^{2}$. Sin embargo la versión de Suárez Marzal no apuesta completamente a un montaje "clásico" que depende exclusivamente del uso del decorado verbal, sino que lo complementa con la proyección de un video digital sobre los blancos espacios de la escenografía. Así la desnuda escenografía se viste con los lugares donde transcurre la acción dramática (pueblo, huerto de Melibea, tierra baldía, torre, escalera, etc.). Cabe destacar que las proyecciones no son estáticas, antes bien están animadas (la tonalidad del cielo cambia, el follaje y las plantas se mueven por el viento, el fuego crepita, etc.) subrayando así la vitalidad del espacio.

Las proyecciones otorgan dinamismo y colorido a la puesta pero no pretenden ocultar la desnudez del escenario. Al presentar una puesta sobria escenográficamente Suárez Marzal privilegia y reafirma el poder de la palabra dramática y del trabajo actoral. Friedrich Dürrenmatt (1955: 24) explica que:

el lugar dramático no existe en el escenario por más escenificado, por más sugestivo que sea el decorado, sino que tiene que surgir de la acción. [...] La fantasía del espectador no necesita más que un ligero apoyo. El decorado quiere insinuar, significar, condensar, no describir.

Es en las palabras, en los versos donde surge el amor y la pasión que después se traducirá en los cuerpos y en el espacio. Ese primer intercambio de palabras entre Calisto y Melibea, una simple pregunta y respuesta, es lo que desata la acción, la violencia y la pasión: "En esto veo Melibea, la grandeza de Dios/ ¿En qué, Calisto?”. Decir el nombre de la persona amada y a la vez escuchar el propio en los labios del Otro es causa y efecto vital. La palabra, así como la mirada, hace germinar el deseo, la lujuria, el amor físico y el espiritual. Para Dürrenmatt (1955: 32) "el diálogo dramático origina: un proceder, un sufrimiento, una situación nueva en que se origina un diálogo nuevo y así sucesivamente".

Si bien no forma parte específicamente de la escenografía, cabe destacar el uso de muñecos durante el desarrollo de ciertos monólogos de Calisto y Melibea. El soliloquio como recurso se presenta ante el público como algo no natural, un recurso cuyo uso es conveniente limitar (Dürrenmatt, 1955: 32). Al utilizar muñecos (vestidos con prendas muy similares a las que usan Calisto y Melibea) se explicitaría, se haría patente el artificio del monólogo; el espectador tomaría distancia permitiendo una recepción y una valoración del soliloquio como forma dramática en sí. De esta manera se evitaría la incomodidad que se experimenta cuando el monólogo se presenta a veces en el marco de cierta concepción mimética o "realista" de la obra teatral. A su vez, los muñecos podrían presentarse como un objeto con el que la actriz y el actor pueden trabajar corporalmente durante el monólogo, con el 
que pueden accionar el texto, hacerlo vivo y vibrante. Los muñecos explicitarían el desdoblamiento de los personajes durante sus confesiones y, al mismo tiempo, evidenciarían que Calisto y Melibea hablan consigo mismo. El monólogo se presenta como un constructo dramático, evitando así la alienación del público.

\section{Vestuario}

El vestuario se establece sobre la dicotomía blanco (Melibea) y negro (Calisto). Dicha dicotomía cromática (o mejor dicho acromática ya que el negro y el blanco son considerados como ausencia de color) representa el binomio mujer-hombre. Desde cierta perspectiva occidental el blanco y el negro se establecen como opuestos y conllevan una carga valorativa maniqueísta. Por otro lado, un punto de vista oriental reconocería las diferencias pero sostendría que se establecen sobre una relación dialéctica, un vínculo de reciprocidad que no seguiría una estricta y absolutista oposición dicotómica. En gran medida la relación de Calisto y Melibea en la puesta de Suárez Marzal se desarrollaría en una forma dialéctica más que como una "atracción por oposición". La puesta de Suárez Marzal no plantea que Calisto y Melibea se enamoran basándose en sus diferencias, antes bien, trataría de resaltar que el vínculo se establece porque los dos comparten un similar y poderoso Eros, un vital deseo erótico.

En un primer momento, a partir del contraste del vestuario, podría pensarse que la puesta de La Celestina presenta a Calisto y Melibea como opuestos, diferenciándose en la expresión de sus sentimientos, en cómo explicitan su deseo, y en la "forma" de comportarse. Pero a medida que transcurre la acción dramática es claro que Melibea y Calisto comparten una misma atracción, un mismo amor físico y espiritual. De hecho en la puesta hay pocas menciones a la diferencia de género. Suárez Marzal plantearía una igualdad en tanto los dos son amantes y enamorados. Melibea expresa su sensualidad y sexualidad de una forma tan patente como lo hace Calisto. Por lo tanto ese vestuario, que en una primera instancia parecía resaltar las diferencias entre los enamorados, evidenciaría cómo Calisto y Melibea se complementan. No hay pares opuestos, hay pares complementarios. Hay un equilibrio basado en la similitud, no en la diferencia.

El diseño de vestuario responde a lo indefinido de la ubicación temporal. La puesta en escena no es historicista o restaurativa (De Toro, 1999: 156) sino que se elige un momento atemporal, el cual está matizado por huellas del cronolecto y dialecto correspondiente a la Castilla de principios de siglo XVI. Con respecto al tiempo y al vestuario Suárez Marzal (Pagés, 2007) explica que "no hay transgresiones pero tampoco adhesiones a una época determinada" y agrega que "nadie podría decir que el traje de Melibea no es un traje de la transición hacia el Renacimiento, pero también podría ser un traje de fiesta de hoy".

El vestuario del personaje de Celestina se aparta de la representación tradicional con ropajes y telas oscuras, grises o pardas. La puesta de Suárez Marzal presenta a una Celestina con una vestimenta con brillantes tonos plateados y matices color hueso. El color de la vestimenta propicia el reflejo de la iluminación, con lo cual podría producirse reverberaciones o un efecto de halo que envuelva a Celestina, resaltando aún más su naturaleza arcana y mística. El vestido de la hechicera y alcahueta está compuesto por diferentes capas y alterna retazos de variados tamaños, redes de nudos y borlas. En comparación con Melibea y Calisto, Celestina luce como alguien que proviene de tiempos arcaicos y primitivos.

\section{Música}

Dos cantantes (Pehuén Díaz Bruno y Nicolás Bernazzani) y un músico (Miguel de Olaso) conforman el espectro musical en la puesta de Suárez Marzal. El compositor Bernazzani (Pagés, 2007) explica 
que "si bien es interpretada por un laudista, la música que elegimos no tiene un anclaje temporal con la obra, simplemente se acerca en el color”. La música en La Celestina (y en otras puestas de Suárez Marzal) no es concebida como un mero acompañamiento, como una sencilla música incidental. Las melodías surgen de la propia obra, están imbricadas y a la vez se originan a partir del texto, de la acción, del movimiento y del espacio.

Son los cantantes y el músico los que inician el relato, son ellos quienes explicitan, como sostenía Bernazzani, el "color" de la obra. La composición e interpretación musical no es subsidiaria de la pieza ni se posiciona en un lugar pasivo. Una obra no se "musicaliza" ya que la música es inherente a ella y al teatro en sí desde sus orígenes rituales.

La interpretación y ejecución en el escenario (en oposición a la reproducción por medio de un soporte técnico) de toda la música de la puesta de La Celestina complementa el tiempo o "ambiente" sugerido de la versión. El seguimiento de ciertos parámetros temporales (una indeterminada época que podría abarcar desde fines de la Edad Media hasta principios del siglo XIX) se refuerza por el hecho de que los cantantes y el músico tienen un vestuario en concordancia con el de los personajes. A su vez la interpretación de los cantores en escena permitiría, a partir de las inflexiones y matices del canto "en vivo", expresar y recrear las pulsaciones vitales derivadas del conflicto dramático y de las transformaciones de los personajes.

La música en la puesta en escena de Suárez Marzal poseería connotaciones de semanticidad, es decir, el sistema acústico sonoro en la escenificación tendría determinadas funciones significantes (Rodríguez, 2006: 207). Determinados teóricos y directores teatrales postulan que la música en escena deber ser asemántica y no figurativa; en contraposición en La Celestina de Suárez Marzal la música establecería subrayados dramáticos y serviría de instrumento de articulación narrativa. La ejecución musical es en sí creación (Veinstein, 1962: 205), intensificando la acción dramática antes que descontextualizarla. La música en La Celestina subraya, amplia y desarrolla los signos de los otros sistemas (Rodríguez, 2006: 209) que entran en juego en la puesta en escena.

Merece destacarse la pieza musical "Requiem", interpretada en el final de la obra. "Requiem" se entona ante Celestina, Calisto y Melibea quienes, ya muertos, avanzan por el espacio escénico hacia el público, como si estuvieran guiados y sostenidos por la lacrimosa.

\section{Conclusión}

Dürrenmatt (1955: 21) observó al teatro contemporáneo y sostuvo que era "uno en dos": a la vez era un museo y un campo de experimentación. El teatro como "museo" es importante y en cierta medida intenta preservar determinados parámetros o estructuras formales consideradas tradicionales o "clásicas". Pero el problema es que un teatro, una puesta en escena completamente "histórica" es una imagen congelada, un corte sincrónico de un momento determinado del desarrollo teatral que permanece inmutable. No hay dinamismo, no hay cambio, no hay recreación. Recorrer o por lo menos considerar el campo experimental abre la puerta a una riqueza semántica y formal que no puede ser desperdiciada. Así lo ha entendido Suárez Marzal al realizar su puesta en escena de La Celestina.

Partiendo de la base de la hibridez genérica de la pieza original, Suárez Marzal realiza una reinterpretación contemporánea de la historia de la Celestina. Si bien Suárez Marzal conservaría el fondo, el color de la obra, no realiza una puesta en escena "museo". Suárez Marzal toma a un clásico y experimenta con él, lo recrea a partir de su puesta para el espectador actual. A través de la síntesis de los personajes y de la conformación del triángulo Calisto-Melibea-Celestina, de un 
espacio escénico despojado e inmóvil pero que cuenta con el movimiento y la versatilidad del video digital, eligiendo un vestuario que subraya los vínculos y lazos entre los personajes, ubicando la acción en un tiempo indeterminado pero que conserva huellas de una época lejana, y por medio de la composición e interpretación musical que nace y que al mismo tiempo da cuenta de los otros sistemas de signos involucrados en la puesta, La Celestina adquiere vida y energía a más de quinientos años de su aparición.

Dice Fernando de Rojas en el prólogo a su obra:

Y pues es antigua querella y visitada de largos tiempos, no quiero maravillarme si esta presente obra ha seýdo instrumento de lid o contienda a sus lectores para ponerlos en differencias, dando cada uno sentencia sobre ella a sabor de su voluntad.

$[\ldots]_{¿}$ Quien negará que aya contienda en cosa que de tantas maneras se entienda? (80-81).

Es el propio Rojas quien admite que la pieza está abierta a múltiples interpretaciones y posicionamientos. Suárez Marzal lee La Celestina en clave contemporánea pero sin renunciar al diálogo con el pasado; al hacerlo ofrece una puesta en escena innovadora manteniendo el poder y la música de la palabra y del lenguaje del cuerpo.

\section{Notas}

1 Rojas, Fernando de. (1994). La Celestina. Introducción y edición a cargo de Dorothy S. Severin. Barcelona: Altaya. Todas las citas de esta edición. Entre paréntesis se indican las páginas de las citas. 2 Para la planta, escenografía y espacio escénico de los corrales de comedia véase: Diez Borque, J. M., ed. (1983). Historia del teatro en España. Tomo I: Edad Media, Siglo XVI, Siglo XVII. Madrid: Taurus. Oleza, Joan, ed. (1986). Teatros y prácticas escénicas, II: la Comedia. Londres: Tamesis Books. Ruano De La Haza, J. M., y Allen, J. J. (1994). Los teatros comerciales y la escenificación de la comedia. Madrid: Castalia.

\section{Bibliografía}

Brecht, Bertolt (1976). Escritos sobre teatro (tomo 3). Selección de Jorge Hacker, traducción de Nélida Mendilaharzu de Machain. Buenos Aires: Nueva Visión.

Cabrera, Hilda. (2007). “Amores y humores trágicos”. Página 12, 31 de agosto.

De Toro, Fernando, (1999). “La(s) teatralidad(es) postmoderna(s). Simulación, deconstrución y escritura rizomática”, en Fernando de Toro, Intersecciones: ensayos sobre teatro. Semiótica, antropología, teatro latinoamericano, post-modernidad, feminismo, post-colonialidad, Frankfurt-Madrid: Veruvert-Iberoamericana.

Deyermond, Alan. (1978). Historia de la literatura española. La Edad Media. Barcelona: Ariel.

Dürrenmatt, Friedrich. (1955). Problemas teatrales. Buenos Aires: Sur.

Green, Otis H. (1991). “Amor cortés y moral cristiana en la trama de La Celestina”. En Alan Deyermond (Ed.). Historia crítica de la literatura española. Edad Media, Barcelona, Crítica, pp. 504-508.

Ivernel, Philippe. (1967). “Pedagogía y política en Bertolt Brecht”. En Jean Jacquot y colaboradores. El teatro moderno: hombres y tendencias. Buenos Aires: EUDEBA, pp. 178- 197.

MacPherson, Ian. (2001). “Descripción y prescripción: el amor en la Baja Edad Media”. En Leonardo Funes y José Luis Moure (Eds.). Studia in honorem Germán Orduna, Universidad de Alcalá, pp. 533-552.

Pagés, Verónica. (2007). “Sólo para tres actores”. La Nación, 29 de agosto. 
Rodríguez, Roberto Pascual. (2006). “Aproximación a la cuestión de la semanticidad del signo musical en el teatro contemporáneo”. Revista de Filología Románica, 23, pp. 205-213.

Rojas, Fernando de. (1994). La Celestina. Introducción y edición a cargo de Dorothy S. Severin, Barcelona: Altaya. Todas las citas de esta edición. Entre paréntesis se indican las páginas de las citas.

Severin, Dorothy S. (1994). “Introducción”. En Fernando de Rojas. La Celestina. Barcelona: Altaya, pp. 9-64.

Veinstein, André. (1962). La puesta en escena. Su condición estética. Buenos Aires: Compañía General Fabril Editora.

\title{
Anexo
}

\section{Ficha técnica}

La Celestina.

De Fernando de Rojas.

Dirección y versión: Daniel Suárez Marzal.

Elenco (por orden de aparición)

Calisto: Sergio Surraco.

Melibea: Julieta Díaz.

Celestina: Elena Tasisto.

Cantante: Pehuén Díaz Bruno.

Cantante y composición musical: Nicolás Bernazzani.

Preparador y músico en escena: Miguel de Olaso.

Coordinación de producción: Beatriz Borquez.

Asistencia de dirección: Silvia Sacco.

Asistencia de vestuario: Andrea Mercado.

Diseño y realización de video digital: Christian Parsons y Paula Spagnoletti.

Iluminación: Nicolás Trovato.

Diseño de vestuario: Renata Schussheim.

Escenografía: Horacio Pigozzi.

Temporada 2007.

Teatro Regio.

\begin{abstract}
Summary: In September of 2007 The Celestine was released in the Regio Theater, in the version written and directed by Daniel Suárez Marzal. The staging of this classic by Fernando de Rojas is product of a reading that privileges a dialogue between past and present. La Celestina by Suárez Marzal is not "an historic based staging" nor "a completely contemporary one", rather it is developed from the synthesis and the reconfiguration of certain classic dramatic and scenic aspects and as much present. This work analyzes the different elements involved in the staging by Suárez Marzal of the piece by Fernando de Rojas.
\end{abstract}

Keywords: Argentine theater directors - Fernando de Rojas - generic hibridization - staging - classic theater - postmodern theater. 
Resumo: Em setembro de 2007 se estreou no Teatro Régio A Celestina, na versão escrita e dirigida por Daniel Suárez Marzal. A posta em cena do clássico de Fernando de Rojas é produto de uma leitura que privilegia um diálogo entre o passado e o presente. A Celestina de Suárez Marzal não é uma posta "historicista" nem uma posta completamente "contemporânea", antes bem se desenvolve a partir da síntese e a reconfiguração de alguns aspectos dramáticos e cênicos tanto clássicos como atuais. O seguinte trabalho analisa os elementos da posta em cena de Suárez Marzal da peça de Fernando de Vermelhas.

Palavras chave: : diretores teatrais argentinos - Fernando de Vermelhas - hibridação genérica - posta em cena - teatro clássico - teatro postmoderno.

${ }^{(*)}$ Licenciado en Letras (UBA). Profesor de la Universidad de Palermo en el Departamento de Proyectos Profesionales en la Facultad de Diseño y Comunicación. Recibió una mención en la categoría “Guión" con "Pirámide" en el segundo Festival Iberoamericano de cortos. 